\title{
PENGARUH DIABETES SELF - MANAGEMENT EDUCATION (DSME) TERHADAP KADAR HbA1C
}

\author{
Ismansyah $^{1}$, Lukman Nulhakim ${ }^{2}$, Rivan Firdaus ${ }^{3}$, Indah Nur Imamah ${ }^{4}$, \\ Reheme Zam Zam Shiera Banu ${ }^{5}$, Tia Puspita Anjani6 \\ 1,2,3,4,5,6 Jurusan Keperawatan, Poltekkes Kemenkes Kalimantan Timur, \\ J1 Wolter Monginsidi No.38 Samarinda75123 \\ Email : isman_rafky@yahoo.co.id
}

\begin{abstract}
Background : Diabetes Self Management Education is a sustainable and comprehensive family-based treatment that involves families in clients' homes with the aim of increasing, maintaining and maximizing client independence and reducing the impact of diabetes. This study aims to determine the effect of DSME towards diabetic patients on HbA1C levels of type 2 diabetes mellitus clients in the working area of Wonorejo Public Health Center, Samarinda.

Method : The design of this study was a quasi-experimental design with a pre and post test with control group design. The population in the study were all patients with diabetes mellitus type 2 in the working area of Wonorejo Public Health Center Samarinda with a total of 32 respondents, by using Simple Random Sampling. The researcher divided the respondents into two groups. Data were analyzed using paired T-Test and Independent T-tests.

Result : The results of this study indicate that the results of statistical tests using the Paired TTest, in the experimental group $\mathrm{p}=0,001$ and $\mathrm{p}=0,002$ in the control group, while the $\mathrm{P}$ value on Independent $\mathrm{T}$-Test is $0,728(\mathrm{p}>\alpha ; \alpha=0,05)$.

Conclusion : There is an influence of DSME on HbA1C levels of patients with DM type 2 in the working area of Wonorejo Public Health Center, Samarinda. It is recommended that health workers can make DSME as a reference in providing health promotion interventions to control $\mathrm{HbA} 1 \mathrm{C}$ levels of patients with $\mathrm{DM}$ type 2 .
\end{abstract}

Keywords : Diabetes Melitus type 2, DSME, HbA1C.

\section{Abstrak}

Latar belakang : Diabetes Self Management Education merupakan perawatan berbasis keluarga yang berkesinambungan dan komprehensif yang melibatkan keluarga di tempat tinggal klien dengan tujuan untuk meningkatkan, mempertahankan dan memaksimalkan kemandirian klien serta mengurangi dampak dari penyakit diabetes. Penelitian ini bertujuan untuk mengetahui pengaruh DSME pada pasien DM tipe 2 terhadap kadar HbA1C klien diabetes melitus tipe 2 di wilayah kerja Puskesmas Wonorejo Samarinda. Metode : Jenis penelitian ini quasi experimental dengan desain penelitian pre-test and posttest with control group design. Populasi dalam penelitian adalah seluruh penderita DM tipe 2 di wilayah Kerja Puskesmas Wonorejo Samarinda dengan jumlah 32 responden, Teknik pengambilan sampelnya yaitu Simple Random Sampling. Peneliti membagi dua kelompok. Data dianalisis dengan menggunakan Paired T-Test dan Independent T-Test.

Hasil Penelitian : Hasil dari penelitian ini menunjukan bahwa hasil uji statistic menggunakan Paired T-Test, pada kelompok eksperimen $\mathrm{p}=0,001$ dan $\mathrm{p}=0,002$ pada kelompok kontrol, sedangkan nilai $\mathrm{P}$ pada Independent T-Test adalah $0,728(\mathrm{p}>\alpha ; \alpha=0,05)$.

Kesimpulan : Ada pengaruh DSME terhadap kadar gula darah pasien DM tipe 2 di wilayah kerja Puskesmas Wonorejo Samarinda. Disarankan tenaga kesehatan dapat menjadikan DSME sebagai acuan dan refrensi dalam memberikan intervensi promosi kesehatan guna mengontrol kadar HbA1C pasien DM tipe 2.

Kata kunci : Diabetes Melitus tipe 2, DSME, HbA1C 


\section{PENDAHULUAN}

Laporan Riset Kesehatan Dasar (Riskesdas) yang menunjukkan prevalensi diabetes mellitus pada penduduk dewasa Indonesia sebesar 6,9\% di tahun 2013, dan melonjak pesat ke angka 8,5\% di tahun 2018 (Kemenkes RI, 2018b).

Menurut Menkes RI, upaya efektif untuk mencegah dan mengendalikan diabetes harus difokuskan pada faktorfaktor risiko disertai dengan pemantauan yang teratur dan berkelanjutan dari perkembangannya karena faktor risiko umum PTM di Indonesia relatif masih tinggi, yaitu $33,5 \%$ tidak melakukan aktivitas fisik, 95\% tidak mengonsumsi buah dan sayuran, dan 33,8\% populasi usia di atas 15 tahun merupakan perokok berat (Kemenkes RI, 2018a).

Pemberian DSME terdiri 2 jam setiap minggu selama 2 minggu berturutturut diikuti dengan sesi pendidikan $2 \times$ 30 menit setelah 3 dan 6 bulan menurunkan kadar HbA1C bagi penderita diabetes. Setelah 6 bulan, HbA1c, glukosa plasma puasa, dan peningkatan kadar glukosa darah postprandial lebih unggul pada kelompok eksperimen dibandingkan dengan kelompok kontrol $(\mathrm{p}<0,05)$ (Ji et al., 2019).

\section{METODE PENELITIAN}

Penelitian dilakukan di Wilayah Kerja Puskesmas Wonorejo Samarinda. Waktu penelitian dilaksanakan pada bulan Maret 2019. Jenis penelitian yang digunakan adalah penelitian eksperimental dengan desain penelitian pre-test and post-test with control group design. Populasi dalam penelitian ini adalah seluruh penderita diabetes di wilayah kerja Puskesmas Wonorejo Samarinda berjumlah 100 orang dengan sampel sebanyak 32 orang menggunakan teknik simple random sampling.

Metode pengumpulan data dilakukan dengan membagi responden menjadi 2 kelompok, yaitu kelompok kontrol dan kelompok Intervensi. Kelompok kontrol diobservasi tanpa dilakukan intervensi, sedangkan kelompok intervensi diobservasi terlebih dahulu (observasi awal/pre-test) sebelum dilakukan intervensi, kemudian diobservasi kembali setelah dilakukan intervensi (post-test). Pemeriksaan HbA1C dilakukan sebelum pemberian DSME dan setelah diberikan DSME selama 3 bulan diukur kembali kadar $\mathrm{HbA1C}$ responden.

Data yang telah dikumpulkan dianalisis secara univariat, dan bivariat menggunakan uji paired T-Test dan 
Independent $\mathrm{T}$-Test untuk mengetahui adanya pengaruh Diabetes Self Management Education dengan kadar HbA1C pasien diabetes melitus.

\section{HASIL DAN PEMBAHASAN}

Tabel 1. Karakteristik Responden berdasarkan Jenis Kelamin, Usia, dan Tingkat Pendidikan pada Kelompok Intervensi dan Kontrol di Puskesmas Wonorejo Samarinda tahun 2019

\begin{tabular}{lcccc}
\hline \multirow{2}{*}{ Karakteristik } & \multicolumn{2}{c}{$\begin{array}{c}\text { Kelompok } \\
\text { Intervensi }\end{array}$} & \multicolumn{2}{c}{$\begin{array}{c}\text { Kelompok } \\
\text { Kontrol }\end{array}$} \\
& $\mathrm{N}$ & $\%$ & $\mathrm{~N}$ & $\%$ \\
\hline Jenis Kelamin & & & & \\
Laki-laki & 3 & 18.75 & 4 & 25 \\
Perempuan & 13 & 81.25 & 12 & 75 \\
Usia (Tahun) & & & & \\
40-55 & 12 & 75 & 9 & 56.25 \\
56-65 & 4 & 25 & 7 & 43.75 \\
Tingkat & & & & \\
Pendidikan & & & & \\
SD & 0 & 0 & 0 & 0 \\
SMP & 9 & 56,25 & 10 & 62,5 \\
SMA/SMK & 5 & 31.25 & 6 & 37,5 \\
S1 & 2 & 12.5 & 0 & 0 \\
$\quad$ Total & 16 & 100 & 16 & 100 \\
\hline
\end{tabular}

Tabel 2. Distribusi Frekuensi Responden Berdasarkan HbA1C pada Kelompok Intervensi di Puskesmas Wonorejo Samarinda, Mei 2019
Tabel 3. Distribusi Frekuensi Responden Berdasarkan HbA1C pada Kelompok Kontrol di Puskesmas Wonorejo Samarinda, Mei 2019

\begin{tabular}{lcccc}
\hline Variabel & $\begin{array}{c}\text { Rerata Pre } \\
\text { Mean } \pm \text { SD }\end{array}$ & $\begin{array}{c}\text { Rerata Post } \\
\text { Mean } \pm \text { SD }\end{array}$ & Selisih & N \\
\hline HbA1C & $9,463 \pm 2,491$ & $7,000 \pm 2,021$ & $2,463 \pm 2,558$ & 16 \\
\hline
\end{tabular}

Tabel 4. Uji Normalitas HbA1C pada Kelompok Intervensi dan Kelompok Kontrol di Puskesmas Wonorejo Samarinda, Mei 2019

\begin{tabular}{|c|c|c|}
\hline \multirow{3}{*}{ HbA1C } & \multicolumn{2}{|c|}{ Saphiro Wilk Test } \\
\hline & Kelompok & Kelompok \\
\hline & Intervensi & Kontrol \\
\hline Pre Test & 0,619 & 0,102 \\
\hline Post Test & 0,054 & 0.082 \\
\hline
\end{tabular}

Tabel 5. Uji Beda Rerata Pre dan Post Pada Kelompok Intervensi dan Kelompok Kontrol di Puskesmas Wonorejo Samarinda, Mei 2019

\begin{tabular}{lccccc}
\hline HbA1C & n & Nilai & Pre test & Post test & p \\
\hline Kelompok & & & & & \\
Intervensi & 16 & Mean \pm SD & $9,469 \pm 2,37$ & $7,262 \pm 2,20$ & 0,001 \\
& & 5 & 2 & \\
Kelompok & & & & & \\
Kontrol & 16 & Mean \pm SD & $9,463 \pm 2,49$ & $7,000 \pm 2,02$ & 0,002 \\
& & & 1 & 1 & \\
\hline
\end{tabular}

Tabel 7. Uji Beda Rerata Perubahan

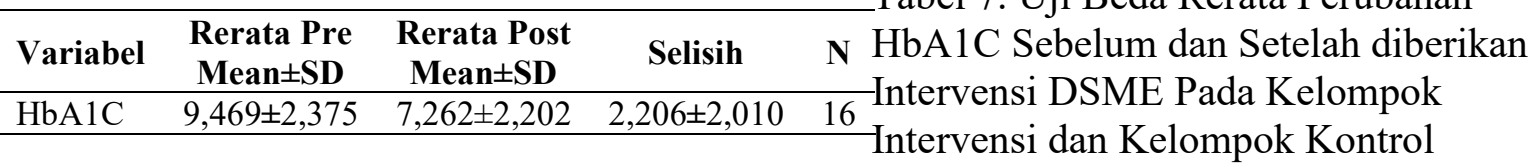

\begin{tabular}{lllll}
\hline \multicolumn{1}{c}{ HbA1C } & Kelompok & N & Mean \pm SD & p \\
\hline Pre Test & & & & \\
HbA1C & Intervensi & 16 & $9,469 \pm 2,375$ & 0,994 \\
& Kontrol & 16 & $9,463 \pm 2,491$ & \\
PostTest & & & & \\
HbA1C & Intervensi & 16 & $7,262 \pm 2,202$ & 0,728 \\
& Kontrol & 16 & $7,000 \pm 2,021$ & \\
\hline
\end{tabular}


Hasil penelitian yang diperoleh melalui uji statistik paired sampel t- test pada kelompok Intervensi didapatkan hasil $\mathrm{p}$ value $=0.001<\mathrm{a}=0,05$ yang berarti ada perbedaan yang signifikan antara rata-rata $\mathrm{HbA} 1 \mathrm{C}$ pre test dengan post test $(\mathrm{Ho}=$ ditolak $)$. Sedangkan hasil penelitian yang diperoleh melalui uji statistik paired sampel t-test pada kelompok Kontrol didapatkan nilai $\mathrm{P}$ value $=0,002<a=0,05$ yang berarti ada perbedaan antara nilai $\mathrm{HbA1C}$ pre test dengan post test $(\mathrm{Ho}=$ ditolak $)$.

DSME bertujuan untuk mendukung pengambilan keputusan, perawatan diri, pemecahan masalah, dan kolaborasi aktif dengan tim kesehatan, sehingga dapat meningkatkan hasil klinis, status kesehatan, serta kualitas hidup (Funnell et al., 2011).

Pemberian DSME ini dapat memberikan hasil baik jangka pendek, jangka menengah, maupun jangka panjang. Hasil dari jangka pendek meliputi kontrol glikemik, kontrol fisik (kadar lipid, mikroalbuminuria, retinopati, berat badan, luka pada kaki serta tekanan darah), pola hidup (kebiasaan merokok, diit, aktifitas fisik), dan status mental (ansietas maupun depresi). Hasil jangka menengah meliputi peningkatan pengetahuan, serta ketrampilan (kontrol gula darah secara mandiri, penggunaan obat-obatan, memecahkan masalah, status psikologis, dan pemanfaatan fasilitas pelayanan kesehatan. Hasil jangka panjang meliputi pencegahan komplikasi mikrovaskuler (penurunan penglihatan, nefropati,neuropati perifer), pencegahan komplikasi makrovaskuler (jantung coroner, vaskuler perifer, serebrovaskuler), penurunan angka kematian, peningkatan kualitas hidup (Norris et al., 2002).

Dari hasil penelitian yang diperoleh melalui uji statistik Independent t-test juga dapat dibandingkan nilai $\mathrm{HbA} 1 \mathrm{C}$ pada kelompok Intervensi dengan kelompok Kontrol, sehingga diperoleh perbedaan nilai $\mathrm{HbA} 1 \mathrm{C}$ pada kedua kelompok. Berdasarkan uji independent T-Test pada tabel nilai pre test $\mathrm{HbA1C}$ didapatkan nilai mean pada kelompok Intervensi adalah 9,469 dan pada kelompok Kontrol adalah 9,463. Sedangkan nilai p 0,994 0,05, hal ini berarti pada pre test di kedua kelompok tidak terdapat perbedaan yang bermakna. Pada uji Independent T-test tabel nilai post test $\mathrm{HbA} 1 \mathrm{C}$ didapatkan nilai mean pada kelompok Intervensi adalah 7,262 dan pada Kelompok Kontrol adalah 7,000 sedangkan nilai p $0,7280,05$, hal 
ini berarti tidak terdapat perbedaan yang cukup bermakna pada post test Kelompok intervensi dan Kelompok kontrol. Jika dilihat dari rata-rata penurunan $\mathrm{HbA1C}$ pada kedua kelompok dapat disimpulkan bahwa tidak ada perbedaan yang bermakna antara Kelompok intervensi dan Kelompok kontrol.

Penelitian ini sejalan dengan penelitian yang dilakukan oleh (Nuradhayani et al., 2017), yang menyatakan terdapat pengaruh dalam pemberian intervensi DSME dan pemberian leaflet diabetes mellitus dalam menahan laju kenaikan kadar glukosa pada penderita diabetes mellitus tipe2, hal ini dibuktikan bahwa jika dibandingkan dengan selisih kenaikan kadar glukosa darah terjadi perubahan yang signifikan dibandingkan dengan kelompok kontrol.

Penelitian lain DSME ini tidak memberikan pengaruh terhadap kadar HbA1C (Pramita \& Aditama, 2013), Penelitian menggunakan desain RCT (randomized control trial) dengan pengambilan sampel secara systematic random sampling. Hasil uji paired t-test pada masing-masing kelompok uji dan kontrol menunjukkan bahwa ada perbedaan yang bermakna antara pengetahuan sebelum dan sesudah edukasi $(\mathrm{p}=0,001$ dan $\mathrm{p}=0,011)$ dan tidak ada perbedaan antara $\mathrm{HbAlc}$ sebelum dan sesudah edukasi $(\mathrm{p}=0.274$ dan $\mathrm{p}=0,166$ ).

Menurut Kristanti (2016) dalam penelitian (Nuradhayani et al., 2017) pada ada saat pelaksanaan DSME berlangsung responden diberikan pemahaman mengenai penyakitnya sehingga responden dapat menyadari kondisi diri dengan penyakit yang diderita, yang kemudian diajak untuk mengelola penyakitnya dan selanjutnya merencanakan tindakan apa saja yang dapat dilakukan dalam mengelola penyakitnya. Sehingga pada akhirnya, edukasi yang diberikan pada responden ini membuat responden dapat menerima penyakitnya dan lebih bijaksana dalam menjalani penyakitnya sehingga dapat meningkatkan kualitas hidup serta meminimalkan terjadinya komplikasi. Dalam mengontrol kadar glukosa darah penderita diabetes mellitus agar tetap stabil dan tidak mengalami komplikasi.

Menurut (Soelistijo et al., 2015) terdapat empat pilar penanganan utama pada penderita diabetes mellitus tipe 2 , yaitu edukasi, terapi nutrisi, latihan jasmani, dan farmakologis. Edukasi ini memegang peranan penting dalam 
penata laksanaan DM tipe 2 karena pemberian edukasi kepada penderita diabetes mellitus dapat merubah perilaku pasien dalam melakukan perawatan mandiri diabetes melitus.

Menurut peneliti, waktu 3 bulan merupakan waktu yang singkat untuk menilai intervensi DSME terhadap kadar HbA1C. Penelitian (Ji et al., 2019) 6 bulan setelah diberikan DSME dan program tambahan edukasi melalui video efektif menurunkan kadar HbA1C. selain itu HbA1C juga dipengaruhi oleh adaanya perdarahan, penyakit gagal ginjal, tranfusi dan minuman beralkohol yang dalam penelitian ini belum dipertimbangkan.

\section{SIMPULAN}

Berdasarkan hasil uji rerata selisih kadar HbA1C, terdapat perbedaan $\mathrm{HbA} 1 \mathrm{C}$ antara yang diberikan Intervensi DSME dan pada kelompok kontrol di wilayah kerja Puskesmas Wonorejo Samarinda.

Hasil penelitian ini diharapkan klien dengan diabetes melitus tipe 2 dapat melanjutkan intervensi yang telah diberikan dan diajarkan dengan benar dan rutin guna mengendalikan serta mencegah terjadinya komplikasi akibat diabetes melitus.

\begin{abstract}
Bagi penelitian selanjutnya diharapkan dapat melakukan pengawasan dan pengontrolan terhadap nutrisi klien secara lebih ketat dengan bekerjasama bersama keluarga serta melakukan pegecekan gula darah selama memberikan intervensi DSME.
\end{abstract}

\section{UCAPAN TERIMA KASIH}

1. Direktur Poltekkes Kemenkes Kalimantan Timur yang telah memfasilitasi penelitian ini

2. Pimpinan Puskesmas Wonorejo Samarinda yang telah memfasilitasi perizinan sebagai lokasi penelitian

\section{DAFTAR PUSTAKA}

Funnell, M. M., Brown, T. L., Childs, B. P., Haas, L. B., Hosey, G. M., Jensen, B., Maryniuk, M., Peyrot, M., Piette, J. D., Reader, D., Siminerio, L. M., Weinger, K., \& Weiss, M. A. (2011). National Standards for diabetes selfmanagement education. Diabetes Care, 34 Suppl 1(Suppl 1), S89-96. https://doi.org/10.2337/dc11-S089

Ji, H., Chen, R., Huang, Y., Li, W., Shi, C., \& Zhou, J. (2019). Effect of simulation education and case management on glycemic control in type 2 diabetes. Diabetes/Metabolism Research and Reviews, 35(3), e3112. https://doi.org/10.1002/dmrr.3112

Kemenkes RI. (2018a). CEGAH, CEGAH, dan CEGAH: Suara 
Dunia Perangi Diabetes. Biro Komunikasi Dan Pelayanan Masyarakat, Kementerian Kesehatan RI. https://www.kemkes.go.id/article/v iew/18121200001/prevent-preventand-prevent-the-voice-of-theworld-fight-diabetes.html

Kemenkes RI. (2018b). Hasil Riset Kesehatan Dasar 2018. In Balitbang Kemenkes RI. https://doi.org/10.1017/CBO97811 07415324.004

Norris, S. L., Nichols, P. J., Caspersen, C. J., Glasgow, R. E., Engelgau, M. M., Jack, L., Snyder, S. R., Carande-Kulis, V. G., Isham, G., Garfield, S., Briss, P., \& McCulloch, D. (2002). Increasing diabetes self-management education in community settings: A systematic review. American Journal of Preventive Medicine, 22(4 SUPPL. 1), 39-66. https://doi.org/10.1016/S07493797(02)00424-5

Nuradhayani, Arman, \& Sudirman. (2017). Pengaruh Diabetes Self Management Education (DSME) Terhadap Kadar Gula Darah Pasien Diabetes Type II Di Balai Besar Laboratorium Kesehatan Makassar. 11, 393-399. http://ejournal.stikesnh.ac.id/index. php/jikd/article/view/243
Pramita, Z., \& Aditama, L. (2013). Efektivitas Edukasi Terapi Insulin terhadap Pengetahuan dan Perbaikan Glikemik Pasien Diabetes Melitus. Indonesian Journal of Clinical Pharmacy, Vol 2, No.

Soelistijo, S., Novida, H., Rudijanto, A., Soewondo, P., Suastika, K., Manaf, A., Sanusi, H., Lindarto, D., Shahab, A., Pramono, B., Langi, Y., Purnamasari, D., \& Soetedjo, N. (2015). Konsesus Pengelolaan Dan Pencegahan Diabetes Melitus Tipe2 di Indonesia 2015. In Perkeni. https://www.google.com/url?sa=t\& source $=$ web $\&$ rct $=\mathrm{j} \&$ url $=\mathrm{https}: / \mathrm{pbp}$ erkeni.or.id/wpcontent/uploads/2019/01/4.Konsensus-Pengelolaan-danPencegahan-Diabetes-melitus-tipe2-di-Indonesia-PERKENI2015.pdf\&ved=2ahUKEwjy8KOs8 cfoAhXCb30KHQb1Ck0QFjADeg QIBhAB\&usg=AOvVaw1PxTUA nZLMkJYCkfCBY1mU 